\section{Correspondence on 'Bowman's capsule rupture on renal biopsy improves the outcome prediction of ANCA-associated glomerulonephritis classifications'}

Bowman's capsule rupture was first reported more than 30 years ago and only few case reports described its presence in diseased kidneys to date. ${ }^{1}$ We read with great interest the recent article by L'Imperio $e t$ al reporting that presence of Bowman's capsule rupture was significantly associated with renal outcome in patients with antineutrophil cytoplasm antibodies (ANCA)-associated glomerulonephritis (GN). ${ }^{2}$ Furthermore, a better performance of the established histopathological subtyping proposed by Berden et al and Brix et al was observed after the implementation of Bowman's capsule rupture to the classification systems. ${ }^{2-4}$ While these findings are of great interest and require further validation, the overall prevalence of Bowman's capsule rupture in ANCA GN remains elusive. Here, we describe the frequency of Bowman's capsule rupture within 44 renal biopsies with confirmed ANCA GN.

In our single-centre cohort, we observed the presence of extensive Bowman's capsule rupture according to L'Imperio et al (figure 1A). Quantitative analysis revealed that this lesion was present in 9/44 (20.5\%) of renal biopsies (figure 1B). Within renal biopsies with Bowman's capsule ruptures, $7.2 \%$ of total and $12.7 \%$ of crescentic glomeruli were affected by this lesion (figure 1C). Interestingly, we also observed focal Bowman's capsule rupture in 23/44 (52.3\%) of renal biopsies (figure 1D,E), affecting $15.7 \%$ of total and $29.2 \%$ of crescentic glomeruli (figure 1F). In summary, extensive Bowman's capsule rupture according to L'Imperio et al was present in a considerable subset of renal biopsies in this cohort. In addition, focal Bowman's capsule rupture with less extensive lesions was observed even more frequently in ANCA GN.

In early stages of ANCA GN, neutrophilic infiltration into the capillary lumen has been proposed with consecutive destruction of the glomerular basement membrane and designated glomerular tuft necrosis, which reflects focal segmental necrotising GN. Thereafter, extracapillary cellular proliferation forms the crescent occupying the glomerular capsule circumference. Progressive inflammation destroys the basement membrane of the Bowman's capsule followed by the recruitment of inflammatory cells into the interstitial lesions surrounding injured glomeruli thereby causing tubulointerstitial damage and tubulointerstitial nephritis. ${ }^{5}$ Since the tubulointerstitial compartment contains peritubular capillaries supplying oxygen for a major fraction of renal parenchyma, it is possible that Bowman's capsule rupture and tubulointerstitial damage may cause local hypoxia,

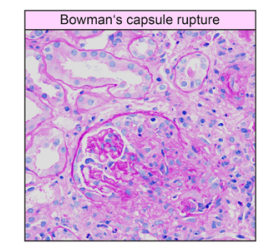

D

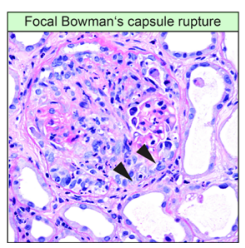

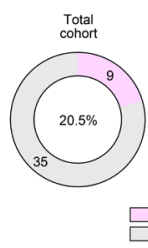

E

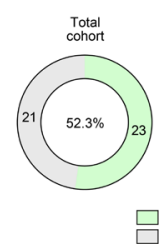

C

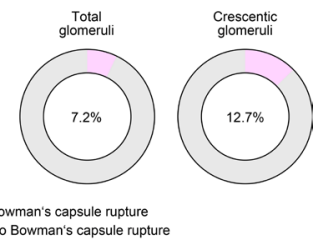

F
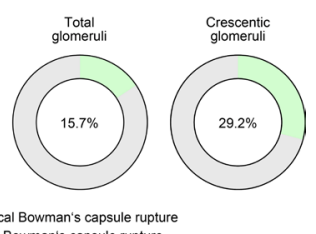

Focal Bowman's capsule rupture
No Bowman's capsule rupture
Figure 1 (A) Representative periodic acid-Schiff reaction (PAS) photomicrograph of extensive Bowman's capsule rupture according to L'Imperio et al. (B) Frequency of extensive Bowman's capsule rupture in the total cohort of 44 renal biopsies. $(C, D)$ Within renal biopsies with extensive Bowman's capsule ruptures, the fractions of total and crescentic glomeruli affected by this lesion are shown. (E) Representative PAS photomicrograph of focal Bowman's capsule rupture. (F) Frequency of focal Bowman's capsule rupture in the total cohort of 44 renal biopsies. $(\mathrm{G}, \mathrm{H})$ Within renal biopsies with focal Bowman's capsule ruptures, the fractions of total and crescentic glomeruli affected by this lesion are shown. aggravating tubular damage and renal outcome in ANCA GN. ${ }^{6}$ Moreover, a relationship between tubulointerstitial and glomerular damage has also been proposed, further supporting an interplay between glomerular and tubulointerstitial lesions.

In conclusion, we show that Bowman's capsule rupture is frequent in ANCA GN and observed in a subset of renal biopsies in our single-centre cohort. Moreover, focal Bowman's capsule rupture with less extensive lesions is even more frequent in ANCA GN. Based on the recent findings by L'Imperio et al that Bowman's capsule rupture was significantly associated with renal outcome in patients with ANCA GN and our observation that Bowman's capsule rupture affects a considerable subset of patients, this issue requires further investigation especially with regard to distinct extensive or focal lesions.

\section{Samy Hakroush, ${ }^{1}$ Björn Tampe ${ }^{2}{ }^{2}$}

${ }^{1}$ Institute of Pathology, University Medical Center Göttingen, Göttingen, Germany ${ }^{2}$ Department of Nephrology and Rheumatology, University Medical Center Göttingen, Göttingen, Germany

Correspondence to Dr Björn Tampe, Department of Nephrology and Rheumatology, University Medical Center Göttingen, 37075 Göttingen, Germany; bjoern.tampe@med.uni-goettingen.de

Contributors BT conceived the correspondence, collected and analysed data and wrote the first draft. SH evaluated renal biopsies and participated in the construction and editing of the manuscript.

Funding The authors have not declared a specific grant for this research from any funding agency in the public, commercial or not-for-profit sectors.

Competing interests None declared.

Patient and public involvement Patients and/or the public were not involved in the design, or conduct, or reporting, or dissemination plans of this research.

\section{Patient consent for publication Not required.}

Ethics approval This study was approved by the institutional review board of the University Medical Center Göttingen, Germany (reference number 4/8/19) and informed written consent was obtained. All data were anonymised to comply with the provisions of personal data protection legislation.

Provenance and peer review Not commissioned; externally peer reviewed.

(C) Author(s) (or their employer(s)) 2021. No commercial re-use. See rights and permissions. Published by BMJ.

\section{Check for updates}

To cite Hakroush S, Tampe B. Ann Rheum Dis Epub ahead of print: [please include Day Month Year]. doi:10.1136/annrheumdis-2021-219970

Received 22 January 2021

Accepted 24 January 2021

\section{SLinked}

- http://dx.doi.org/10.1136/annrheumdis-2021-219988

Ann Rheum Dis 2021:0:1. doi:10.1136/annrheumdis-2021-219970

\section{ORCID iD}

Björn Tampe http://orcid.org/0000-0002-4357-9863

\section{REFERENCES}

1 Boucher A, Droz D, Adafer E, et al. Relationship between the integrity of Bowman's capsule and the composition of cellular crescents in human crescentic glomerulonephritis. Lab Invest 1987;56:526-33.

2 L'Imperio V, Vischini G, Pagni F, et al. Bowman's capsule rupture on renal biopsy improves the outcome prediction of ANCA-associated glomerulonephritis classifications. Ann Rheum Dis 2020. doi:10.1136/annrheumdis-2020-217979. [Epub ahead of print: 12 Jun 2020].

3 Berden AE, Ferrario F, Hagen EC, et al. Histopathologic classification of ANCAassociated glomerulonephritis. J Am Soc Nephrol 2010;21:1628-36.

4 Brix SR, Noriega M, Tennstedt P, et al. Development and validation of a renal risk score in ANCA-associated glomerulonephritis. Kidney Int 2018;94:1177-88.

5 Joh K, Muso E, Shigematsu H, et al. Renal pathology of ANCA-related vasculitis: proposal for standardization of pathological diagnosis in Japan. Clin Exp Nephrol 2008; 12:277-91.

6 Ohashi R, Kitamura H, Yamanaka N. Peritubular capillary injury during the progression of experimental glomerulonephritis in rats. J Am Soc Nephrol 2000;11:47-56.

7 Fine LG, Ong AC, Norman JT. Mechanisms of tubulo-interstitial injury in progressive renal diseases. Eur J Clin Invest 1993:23:259-65. 